\title{
Erratum to: Lack of Associations of Neuregulin 1 Variations with Schizophrenia and Smooth Pursuit Eye Movement Abnormality in a Korean Population
}

\author{
Jeong-Hyun Kim • Byung-Lae Park • Charisse Flerida A. Pasaje • Joon Seol Bae • \\ Chul Soo Park • Boseok Cha • Bong-Jo Kim • Migyung Lee • Woo Hyuk Choi • \\ Tae-Min Shin • Ihn-Geun Choi • Jaeuk Hwang • InSong Koh • Sung-Il Woo • \\ Hyoung Doo Shin
}

Published online: 18 November 2011

(C) Springer Science+Business Media, LLC 2011

\section{Erratum to: J Mol Neurosci}

$$
\text { DOI 10.1007/s12031-011-9619-y }
$$

The original version of this article unfortunately contained a mistake. The change is underlined as follows.

\section{Materials and Methods}

Subjects

"In this study, we recruited a total of 825 individuals including 435 schizophrenia patients enrolled in Jinju Mental Hospital,

The online version of the original article can be found at http://dx.doi. org/10.1007/s12031-011-9619-y.

J.-H. Kim • C. F. A. Pasaje · J. S. Bae $\cdot$ H. D. Shin $(\bowtie)$

Department of Life Science, Sogang University,

Seoul 121-742, Republic of Korea

e-mail: hdshin@sogang.ac.kr

B.-L. Park $\cdot$ H. D. Shin

Department of Genetic Epidemiology, SNP Genetics, Inc,

Seoul, Republic of Korea

C. S. Park $\cdot$ B. Cha $\cdot$ B.-J. Kim

Department of Psychiatry, College of Medicine, Gyeongsang

National University,

Jinju, Republic of Korea

\section{Lee}

Department of General Psychiatry, Seoul National Hospital,

Seoul, Republic of Korea

W. H. Choi · T.-M. Shin

Department of Biomedical Engineering, Yonsei University,

Wonju, Republic of Korea
Soonyoung Hospital, Hadong Wooridle Hospital (Gyeongsang Nam Do, Korea), Seoul National Hospital (Seoul, Korea) and Keyo Hospital (Kyunggi-Do, Korea) and 390 unrelated healthy controls in a Korean population."

\author{
J. Hwang $\cdot$ S.-I. Woo $(\bowtie)$ \\ Department of Neuropsychiatry, \\ Soonchunhyang University Hospital, \\ Seoul 140-743, Republic of Korea \\ e-mail: siwoo@hosp.sch.ac.kr
}

I. Koh

Department of Physiology, College of Medicine,

Han Yang University,

Seoul, Republic of Korea 